\title{
Short communication: Promotion of glucagon-like peptide-2 secretion in dairy calves with a bioactive extract from Olea europaea
}

\author{
S. Y. Morrison, ${ }^{*}$ J. J. Pastor,† J. C. Quintela,‡ J. J. Holst,§ B. Hartmann,§ J. K. Drackley, \\ and I. R. Ipharraguerre†\# \\ *Department of Animal Science, University of Illinois, Urbana 61801 \\ †Lucta S. A., Montornès del Vallès, Spain 08170 \\ †ProNutra Solutions, Madrid, Spain 28049 \\ $\S$ The NNF Center for Basic Metabolic Research and Department of Biomedical Sciences, Faculty of Health Sciences, University of Copenhagen, \\ Denmark 2200 \\ \#Institute of Human Nutrition and Food Science, Kiel University, Kiel, Germany D-24098
}

\begin{abstract}
Diarrhea episodes in dairy calves involve profound alterations in the mechanism controlling gut barrier function that ultimately compromise intestinal permeability to macromolecules, including pathogenic bacteria. Intestinal dysfunction models suggest that a key element of intestinal adaptation during the neonatal phase is the nutrient-induced secretion of glucagon-like peptide (GLP)-2 and associated effects on mucosal cell proliferation, barrier function, and inflammatory response. Bioactive molecules found in Olea europaea have been shown to induce the release of regulatory peptides from model enteroendocrine cells. The ability to enhance GLP-2 secretion via the feeding of putative GLP-2 secretagogues is untested in newborn calves. The objectives of this study were to determine whether feeding a bioactive extract from Olea europaea (OBE) mixed in the milk replacer (1) can stimulate GLP-2 secretion beyond the response elicited by enteral nutrients and, thereby, (2) improve intestinal permeability and animal growth as well as (3) reduce the incidence of diarrhea in preweaning dairy calves. Holstein heifer calves $(\mathrm{n}=60)$ were purchased, transported to the research facility, and blocked by body weight and total serum protein and assigned to 1 of 3 treatments. Treatments were control $(\mathrm{CON})$, standard milk replacer (MR) and ad libitum starter; CON plus OBE added into $\mathrm{MR}$ at $30 \mathrm{mg} / \mathrm{kg}$ of body weight (OBE30); and CON plus OBE added into $\mathrm{MR}$ at $60 \mathrm{mg} / \mathrm{kg}$ of body weight (OBE60). The concentration of GLP-2 was measured at the end of wk 2. Intestinal permeability was measured at the onset of the study and the end of wk 2 and 6, with lactulose and D-mannitol as markers. Treatments did not affect calf
\end{abstract}

Received August 1, 2016.

Accepted November 5, 2016.

${ }^{1}$ Corresponding author: ipharraguerre@foodsci.uni-kiel.de growth and starter intake. Compared with CON, administration of OBE60 increased the nutrient-induced response in GLP-2 by about 1 fold and reduced MR intake during the second week of study. Throughout the study, however, all calves had compromised intestinal permeability and a high incidence of diarrhea. The GLP-2 response elicited by OBE60 did not improve intestinal permeability (lactulose-to-D-mannitol ratio) and incidence of diarrhea over the course of the preweaning period. The response in GLP-2 secretion to the administration of OBE reported herein warrants further research efforts to investigate the possibility of improving intestinal integrity through GLP-2 secretion in newborn calves.

Key words: glucagon-like peptide-2 (GLP-2), intestine, permeability, dairy calf

\section{Short Communication}

Intestinal disorders are common in newborn calves. A survey conducted in the United States in 2011 showed that about $25 \%$ of preweaned heifers had diarrhea and that diarrhea or other digestive problems accounted for $31 \%$ of the preweaning heifer mortality (NAHMS, 2011). Neonatal diarrhea is frequently observed from 3 to $21 \mathrm{~d}$ of age, but its onset and duration is determined by the number of pathogens involved and the immune condition of the animal (Butler and Clark, 1994). Regardless of the etiology, diarrhea episodes involve profound alterations in the mechanism controlling gut barrier function that ultimately compromise intestinal permeability to macromolecules, including pathogenic bacteria.

Past and recent studies in pig models of intestinal dysfunction suggest that a key element of intestinal adaptation during the neonatal and early postweaning phases is the nutrient-induced secretion of GLP-2 and associated effects on mucosal cell proliferation, barrier 
function, and inflammatory response (Burrin et al., 2003; Cameron and Perdue, 2005; Sigalet et al., 2007; Ipharraguerre et al., 2013). In calves, episodes of diarrhea are associated with decreases in intake, and we have recently shown that the concentration of circulating GLP-2 decreases remarkably when ingestion drops below $0.875 \%$ of the calf BW (Castro et al., 2016). In addition to nutrients, however, bioactive molecules extracted from Olea europaea have been shown to induce the secretion of GLP-1, which is co-secreted with GLP-2, in model enteroendocrine cells via activation of the bile acid receptor TGR5 (Bala et al., 2014). Furthermore, recent work in newborn or weanling piglets showed that the enteral administration of the primary bile acid chenodeoxycholic acid, a TGR5 agonist, to newborn or weanling piglets increases endogenous GLP-2 secretion and intestinal growth (Jain et al., 2012; Ipharraguerre et al., 2013).

The ability to enhance endogenous GLP-2 secretion via the feeding of plant-derived GLP-2 agonists is an attractive and yet unexplored approach for promoting intestinal adaptation and function in newborn calves. If this expectation is met, then the incidence of intestinal disorders and associated preweaning growth limitation should be reduced. The objectives of our study were to determine whether an extract from Olea europaea (OBE; Lucta S.A., Montornes del Valles, Spain), with a high content of polyphenols, triterpenic acids, long-chain fatty alcohols, unsaturated hydrocarbons, tocopherols and sterols with antioxidative and anti-inflammatory properties, (1) can stimulate GLP-2 secretion beyond the response elicited by enteral nutrients and thereby (2) improve intestinal permeability and animal growth as well as (3) reduce the incidence of diarrhea in preweaning dairy calves.

All procedures used in this experiment were approved by the University of Illinois Institutional Animal Care and Use Committee. Sixty heifer calves, less than $1 \mathrm{wk}$ old, were purchased from a cattle dealer in southern Wisconsin and transported (approximately $470 \mathrm{~km}$ and $5 \mathrm{~h}$ transport time) to the University of Illinois Nutrition Field Laboratory research site (Urbana, IL). Animals were brought in 2 groups (batch) of 30 calves 2 wk apart to facilitate processing and early sample collection. At arrival, calves were rehydrated with an oral electrolyte solution (C.H.E.E.R.S., Nouriche Nutrition Ltd., St. Louis, MO). An hour after electrolyte administration, blood samples were taken from the jugular vein into a $10-\mathrm{mL}$ evacuated serum separation tube (Becton Dickinson, Rutherford, NJ). Blood was kept at room temperature for $20 \mathrm{~min}$ and centrifuged at $1,300 \times g$ for $15 \mathrm{~min}$ at $20^{\circ} \mathrm{C}$. A refractometer was used to determine total protein from the serum for all calves. Initial measurements of BW, body length, heart girth, withers height, hip height, and hip width were obtained at the same time as blood sampling. All calves were given $2 \mathrm{~mL}$ of BO-SE (Merck Animal Health, Kenilworth, NJ), $1 \mathrm{~mL}$ of vitamin $\mathrm{A}$ and $\mathrm{D}$ (Sparhawk Laboratories Inc., Lenexa, KS), and $2 \mathrm{~mL}$ of Inforce (Pfizer, New York, NY).

This study was conducted as a randomized block design. At arrival and within the 2 batches, calves were blocked by initial BW and TP and then randomly assigned within block to 1 of 3 treatments. Calves were allowed to acclimatize to their new environment for 1 $\mathrm{d}$ before treatments were first administered. The treatments were standard milk replacer (MR) and ad libitum starter (control; CON); CON with OBE dosed in the $\mathrm{MR}$ at $30 \mathrm{mg} / \mathrm{kg}$ of BW (OBE30); and CON with OBE dosed in the MR at $60 \mathrm{mg} / \mathrm{kg}$ of BW (OBE60). The doses of OBE were estimated using allometric scaling of the amount of OBE required to induce GLP-2 secretion in weanling pigs in a pilot study and were adjusted weekly based on the corresponding dose and calf BW. The total amount of OBE fed to each calf was divided in 2 so that half of the daily allotment was given at each MR feeding.

Calves were housed in south-facing individual hutches (Calf-tel, Hampel Corp., Germantown, WI) placed 1.5 $\mathrm{m}$ apart from one another. Calves were fed twice daily at 0500 and $1630 \mathrm{~h}$. The MR was a commercial $28.5 \%$ $\mathrm{CP}$ and $15 \%$ fat formula (Milk Specialties Global, Eden Prairie, MN) reconstituted to $15 \%$ solids. The feeding rate of MR per calf was $500 \mathrm{~g} / \mathrm{d}$ during $\mathrm{d} 1$ and 2, 750 $\mathrm{g} / \mathrm{d}$ from d 3 to $7,1,000 \mathrm{~g} / \mathrm{d}$ from d 8 to 42 , and 500 $\mathrm{g} / \mathrm{d}$ from d 43 to 49 . The intake of MR was recorded daily. Calf starter and water were offered for ad libitum consumption for the duration of the trial and intake was recorded daily. After d 49, MR was removed completely and only starter and water were given. Body weight, body length, heart girth, withers height, hip height, and hip width were measured weekly for the duration of the trial. Body weight and growth measures were obtained after the morning feeding. The assessment of intestinal permeability was conducted during the day before treatment initiation (d 0), 2 wk after treatment exposure (d 13), and during the week before weaning (d 41). To this end, lactulose $(0.5 \mathrm{~g} / \mathrm{kg}$ of BW) and D-mannitol $(0.1 \mathrm{~g} / \mathrm{kg}$ of BW) were used as permeability markers and administered in the MR during the morning feeding (Hall, 1999). One hour after feeding (dosing) blood was collected via jugular venipuncture into a $10-\mathrm{mL}$ evacuated serum separation tube and a 10-mL $\mathrm{K}_{2}$ EDTA-coated blood collection tube (Becton Dickinson). Blood for serum separation was allowed to clot at room temperature and then centrifuged at 1,300 $\times g$ for $15 \mathrm{~min}$ at $20^{\circ} \mathrm{C}$. Serum and plasma were divided into aliquots in polypropylene tubes and stored at 
$-20^{\circ} \mathrm{C}$ until analyzed. Determination of serum lactulose and D-mannitol concentrations was performed by ultraHPLC-MS (Xevo G2 Tof, Waters, Milford, MA) with an electrospray ionization source operating in negative mode. Serum extract was injected $(5 \mu \mathrm{L})$ onto a $\mathrm{BEH}$ amide column $(2.1 \mathrm{~mm} \times 100 \mathrm{~mm}, 1.7 \mu \mathrm{m}$, Waters $)$. The mobile phases were water and $0.1 \% \mathrm{NH}_{4} \mathrm{OH}$, and methanol and $0.1 \% \mathrm{NH}_{4} \mathrm{OH}$. Elution conditions, at a flow rate of $0.3 \mathrm{~mL} / \mathrm{min}$, were $90 \%$ methanol $+0.1 \%$ $\mathrm{NH}_{4} \mathrm{OH}$ maintained for $2 \mathrm{~min}$, linear gradient from 90 to $60 \%$ in $4 \mathrm{~min}$, and equilibration to initial conditions over 4 min. Column and auto-sampler chamber temperatures were maintained at 45 and $4^{\circ} \mathrm{C}$, respectively. The operating conditions were source temperature $=$ $120^{\circ} \mathrm{C}$; desolvation temperature $=350^{\circ} \mathrm{C}$; desolvation gas $=900 \mathrm{~L} / \mathrm{h}$; cone gas $=10 \mathrm{~L} / \mathrm{h}$; capillary voltage $=$ $0.5 \mathrm{kV}$; cone voltage $=30 \mathrm{~V}$; and extraction cone $=4$ V. Leucine enkephalin at a concentration of $2 \mu \mathrm{g} / \mathrm{mL}$ was used as a lock mass for mass accuracy and infused at a flow of $5 \mu \mathrm{L} / \mathrm{min}$. Chromatograms were processed using Quanlynx software (v4.1, Waters).

On d 12, blood samples were collected into $10-\mathrm{mL}$ tubes containing EDTA (Becton Dickinson) plus a pyrrolic acid-based dipeptidyl peptidase 4 inhibitor (cata$\log$ \#: DPP4, EMD Millipore, St. Charles, MO) before feeding and $1 \mathrm{~h}$ after feeding. Samples were kept on ice for 15 min after collection and then centrifuged at room temperature for $15 \mathrm{~min}$ at $2,500 \times \mathrm{g}$. The plasma was extracted, put in liquid nitrogen, and stored at $-20^{\circ} \mathrm{C}$ until further analyses. All plasma samples $(700 \mu \mathrm{L})$ were extracted in a final concentration of $75 \%$ ethanol before GLP-2 measurements as previously described (Taylor-Edwards et al., 2010). Intact GLP-2 was measured using a radioimmunoassay as previously described (Hartmann et al., 2000). Briefly, the antiserum (code no. 92160), developed as described in Wøjdemann et al. (1998), is directed against the N terminus of GLP-2 and, therefore, measures only fully processed GLP-2 of intestinal origin. For standards, we used recombinant human GLP-2 and the tracer was ${ }^{125}$ I-labeled rat GLP2 with an Asp33 $\rightarrow$ Tyr33 substitution. The sensitivity was $2 \mathrm{pmol} / \mathrm{L}$ and intra-assay coefficient of variation below $6 \%$.

Data were analyzed using PROC GLIMMIX of SAS version 9.4 (SAS Institute Inc., Cary, NC). For Gaussian data (intake, MR intake as a percentage of BW, ADG, gain-to-feed ratio, permeability, and GLP-2 concentration) the model of variance analysis included treatment, time as a repeated measure (when appropriate), and their interaction as fixed effects. Block and batch were included as random effects in all models; however, block was not significant and therefore not used for statistical analyses. Initial measures of calf $\mathrm{BW}$ were included as a covariate for intake, BW, ADG, and gain-to-feed ratio. Because enteral nutrient supply is the primary stimulus for GLP-2 secretion (Burrin and Stoll, 2003), results for GLP-2 concentrations were analyzed unadjusted and covariate-adjusted using mean MR intake during the first 2 wk of study as covariate. Binary data (occurrence of diarrhea) were analyzed with a binomial distribution with a logit link function and included treatment and time as repeated measures and their interaction as fixed effects. Count data (days with diarrhea) were analyzed with a negative binomial distribution using a log link function with the fixed effect of treatment. Akaike information criterion was used to select the best covariate structure. Residuals were checked for homogeneity of variance and normality assumptions by residual plots and extended Levene test. Heterogeneous variances were handled by implementing error structures that allow for heterogeneous variances (Littell et al., 2006). Significance was set at $P$ $\leq 0.10$ and results were separated using Tukey adjustment. Additionally, the magnitude of treatment effect on the plasma concentration of GLP-2 (effect size) was assessed by calculating the 90 and $95 \%$ confidence intervals for the quotient between treatment (OBE30 and OBE60) and control group. Data are reported as least squares means according to treatment effects if no interactions are significant, or according to the highestorder interaction detected.

We found no differences in final BW at wk 7 (73.8, 71.3 , and $74.1 \pm 2.5 \mathrm{~kg}$ for CON, OBE30, and OBE60, respectively), $\mathrm{ADG}(651.2,608.4$, and $641.0 \pm 58.6$ $\mathrm{g} / \mathrm{d}$ for CON, OBE30, and OBE60, respectively), gain-to-feed ratio $(0.60,0.58$, and $0.59 \pm 0.06 \mathrm{~kg} / \mathrm{kg}$ for CON, OBE30, and OBE60, respectively), or body conformation measurements $(P>0.10)$ among treatments throughout the experiment (data not shown). The prefeeding concentration of GLP-2 in plasma was similar among treatments (Table 1). Upon MR feeding, GLP-2 increased for all groups albeit to a greater extent for the OBE treatments $(P<0.06)$. Compared with CON, however, this response was significantly higher only for the OBE60 group $(P=0.05)$. Estimation of the OBE effect size (Figure 1) indicates that OBE60 increased GLP-2 relative to CON on average by about 1 fold ( $33 \mathrm{pmol} / \mathrm{L})$, and that, depending on the confidence level, this response could have reached up to either 5 (65 pmol/L; $90 \% \mathrm{CI})$ or 7 fold $(72 \mathrm{pmol} / \mathrm{L}$; $95 \%$ CI). These results are in line with previous data from in vitro and in vivo studies demonstrating that targeting TGR5 with endogenous (Jain et al., 2012; Ipharraguerre et al., 2013) or exogenous agonists (Katsuma et al., 2005; Thomas et al., 2009) has the potential to stimulate GLP-2 secretion.

The secretion of GLP-2 is mainly driven by the amount of feed ingested by calves (Castro et al., 2016). 
Table 1. Concentrations of glucagon-like peptide-2 (GLP-2) and permeability markers in plasma of dairy calves fed OBE in milk replacer during the preweaning period (wk 1-7)

\begin{tabular}{|c|c|c|c|c|c|c|c|}
\hline \multirow[b]{2}{*}{ Variable } & \multicolumn{3}{|c|}{ Treatment $^{1}$} & \multirow[b]{2}{*}{$\mathrm{SE}$} & \multicolumn{3}{|c|}{$P$-value } \\
\hline & $\mathrm{CON}$ & OBE30 & OBE60 & & Treatment & Time & $\begin{array}{l}\text { Treatment } \\
\quad \times \text { time }\end{array}$ \\
\hline \multicolumn{8}{|l|}{ GLP-2 ${ }^{2}$} \\
\hline Prefeeding & 30.6 & 31.8 & 30.4 & 3.2 & 0.95 & - & - \\
\hline Postfeeding & 67.5 & 72.9 & 100.4 & 11.7 & 0.13 & - & - \\
\hline Delta $^{3}$ & $36.9^{\mathrm{b}}$ & $42.4^{\mathrm{ab}}$ & $69.9^{\mathrm{a}}$ & 13.2 & 0.06 & - & - \\
\hline \multicolumn{8}{|l|}{ Adjusted GLP-2 $2^{4}$} \\
\hline Prefeeding & 30.6 & 31.8 & 30.4 & 3.2 & 0.94 & - & - \\
\hline Postfeeding & 68.3 & 72.3 & 100.1 & 11.9 & 0.15 & - & - \\
\hline Delta $^{3}$ & $38.4^{\mathrm{b}}$ & $41.6^{\mathrm{b}}$ & $69.4^{\mathrm{a}}$ & 14.1 & 0.07 & - & - \\
\hline \multicolumn{8}{|l|}{ Permeability indicators } \\
\hline Mannitol, ${ }^{5} \mu \mathrm{g} / \mathrm{mL}$ & 1.32 & 1.33 & 1.30 & 0.09 & 0.98 & $<0.0001$ & 0.99 \\
\hline Lactulose, ${ }^{5} \mu \mathrm{g} / \mathrm{mL}$ & 33.64 & 33.98 & 34.33 & 0.92 & 0.87 & $<0.0001$ & 0.65 \\
\hline Lactulose/D-mannitol ${ }^{5}$ & 27.56 & 27.21 & 28.30 & 1.56 & 0.88 & $<0.0001$ & 0.77 \\
\hline
\end{tabular}

${ }_{\mathrm{a}, \mathrm{b}}$ Means within a row with different superscripts differ $(P=0.05)$.

${ }^{1} \mathrm{CON}=$ control, OBE30 = bioactive extract from Olea europaea fed in the milk replacer at $30 \mathrm{mg} / \mathrm{kg}$ of BW, OBE60 = bioactive extract from Olea europaea fed in the milk replacer at $60 \mathrm{mg} / \mathrm{kg}$ of BW.

${ }^{2}$ GLP-2 sampled during wk 2 immediately before milk replacer feeding (prefeeding) and 60 min after milk replacer feeding (postfeeding).

${ }^{3}$ Delta $=$ postfeeding GLP-2 concentration - prefeeding GLP-2 concentration.

${ }^{4}$ GLP-2 concentrations adjusted using mean milk replacer intake during the first 2 wk of study as covariate.

${ }^{5}$ Mannitol, lactulose, and lactulose/D-mannitol measured wk 0, 2, and 6 .

Although we found no differences $(P>0.10)$ in starter intake $(251.2,188.5$, and $258.4 \pm 38.9 \mathrm{~g} / \mathrm{d}$ for CON, OBE30, and OBE60, respectively) or total DM ingestion $(1,096.5,1,028.5$, and $1,093.3 \pm 44.0 \mathrm{~g} / \mathrm{d}$ for CON, OBE30, and OBE60, respectively) among experimental

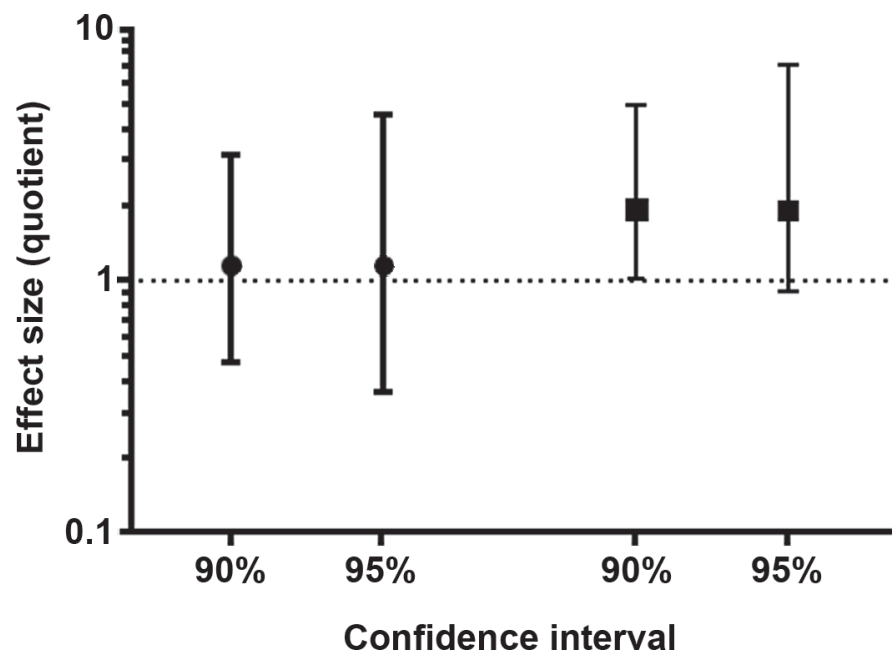

Figure 1. Confidence intervals of the quotient between treatments and control (effect size) for the change in plasma GLP-2 concentration in response to feeding of a bioactive extract from Olea europaea (OBE) in the milk replacer (delta) to heifer Holstein calves. OBE30/CON $(\mathbf{)})$ bioactive extract from Olea europaea fed in the milk replacer at $30 \mathrm{mg} / \mathrm{kg}$ of BW followed by control; OBE60/CON $(\mathbf{\square})=$ bioactive extract from Olea europaea fed in the milk replacer at $60 \mathrm{mg} / \mathrm{kg}$ of BW followed by control. groups, we did note a treatment by time interaction $(P<0.03)$ for the consumption of MR during the preweaning period. This interaction was caused by OBE60 calves, which consumed less MR than CON and OBE30 calves during the wk 2 of the study ( 869 vs. 937 and $929 \mathrm{~g} / \mathrm{d}$, respectively). Importantly, after wk 2, all calves achieved similar MR intake, which averaged 953 $\mathrm{g} / \mathrm{d}$ until weaning. This finding suggests that poor MR palatability resulting from the feeding of $\mathrm{OBE}$ at the highest dose could not have played a role in limiting MR intake of OBE60 calves. As indicated below, differences in disease load among treatments did not appear either to account for the described alterations in MR intake. Alternatively, such a response could be attributed to the anorectic properties of GLP-2 (Guan, 2014) and, in particular, of the co-secreted GLP-1 (Turton et al., 1996), whose plasma concentration also should have increased in response to the administration of OBE60. However, intake of $\mathrm{MR}$ as a percentage of $\mathrm{BW}$ was not different $(P>0.10)$ and averaged $1.5 \%$ of $\mathrm{BW}$ for all treatments. This feeding level is well above the critical point for GLP-2 secretion identified by Castro et al. (2016) of $0.875 \%$ of BW in preweaned dairy calves, at which point GLP-2 secretion is significantly reduced. Certainly, adjusting GLP-2 concentration using MR intake as a covariate did not alter the aforementioned effect of OBE60 on the pre- and postfeeding circulating concentrations of GLP-2 (Table 1). Therefore, the difference in MR intake during wk 2 likely had minimal effects on GLP-2 secretion because the attained feed- 
ing rate should have promoted near maximal nutrientdependent secretion of GLP-2 for all treatments.

The incidence of diarrhea was high in our study, suggesting that all calves were highly challenged with enteric pathogens. Across treatments, calves were 3.88 and 9.93 times more likely $(P<0.0001)$ to have diarrhea in wk 1 compared with wk 2 and 3 , respectively. Additionally, calves were 2.56 times more likely $(P<$ $0.0001)$ to develop such a disease in wk 2 than 3 . In relation to treatment groups, $\mathrm{CON}$ animals were 0.62 and 0.54 times less likely $(P<0.001)$ to have scours than OBE30 and OBE60 calves, respectively. During the first $3 \mathrm{wk}$ of study, however, we found no differences between OBE30 and OBE60 calves for the incidence of scours. Furthermore, during the same period the number of days with diarrhea did not differ $(P=0.32)$ among treatments groups $(7.05,8.35$, and $9.05 \mathrm{~d}$ with diarrhea for CON, OBE30, and OBE60 calves, respectively).

Enteric challenges result in disruption of intestinal barrier by altering the tight junction proteins or causing damage to enterocytes (Sears, 2000; Groschwitz and Hogan, 2009; Ulluwishewa et al., 2011). The lactulose/D-mannitol test has been validated to assess small intestine permeability in many species, including calves (Hall, 1999; Klein et al., 2007). Lactulose is a marker of the paracellular permeability in the small intestine, or unrestricted entry of macromolecules, whereas mannitol is a marker of the transcellular absorption of small molecules (Bjarnason et al., 1995; Hall, 1999). The lactulose-to-D-mannitol ratio was not affected by treatment or its interaction with time $(P>0.10)$, but we found a significant time effect $(P<0.0001)$. The evolution of intestinal permeability illustrated by the lactulose-to-D-mannitol ratio indicates that permeability increased remarkably at 2 wk of age for all treatment groups (Figure 2). This high serum lactulose-toD-mannitol ratio would suggest damaged villi in the small intestine, allowing greater flux of large molecules across the intestinal mucosa during wk 2 (Hall, 1999). These results agree with the aforementioned incidence of diarrhea and findings from Araujo et al. (2015), who showed diarrheic calves had higher serum lactulose-toD-mannitol ratios even soon after birth. It is important to note that the serum lactulose levels observed in our study were 2.2 times greater than those observed by Araujo et al. (2015) in diarrheic calves, highlighting the compromised intestinal integrity of calves across all treatments in this trial. Furthermore, the lactuloseto-D-mannitol ratio observed in our study is also much higher than other studies have reported in dairy calves across all time points (Branco Pardal et al., 1995; Klein et al., 2007, 2008). Previous studies have shown greater

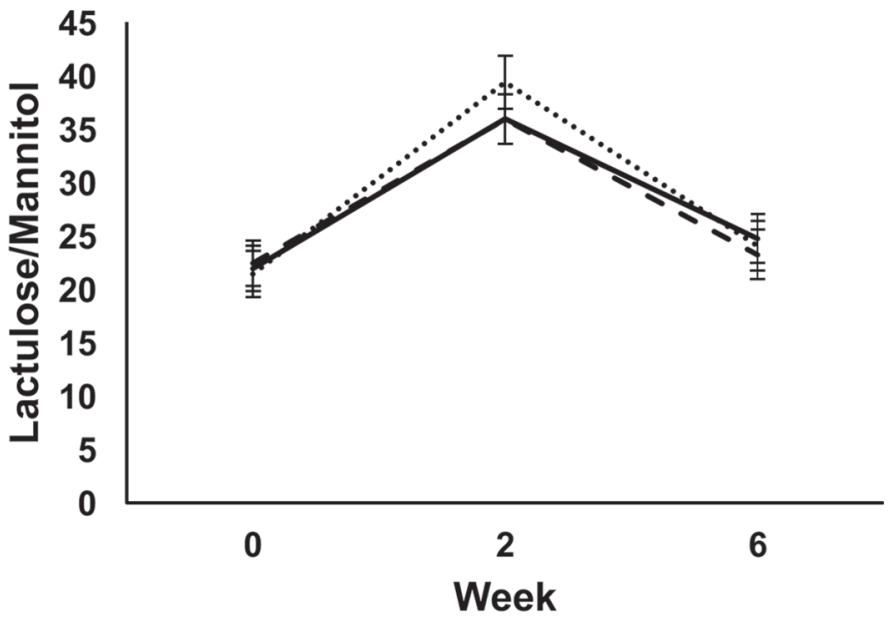

Figure 2. Evolution of lactulose-to-D-mannitol ratio in heifer Holstein calves fed a milk replacer (CON; solid line), or the same milk replacer supplemented with a bioactive extract from Olea europaea at $30 \mathrm{mg} / \mathrm{kg}$ of BW (OBE30; dashed line) or $60 \mathrm{mg} / \mathrm{kg}$ of BW (OBE60; dotted line) over a 6 -wk time period (treatment: $P=0.88$; time: $P<$ 0.001; treatment $\times$ time: $P=0.77)$. Values are $\mathrm{LSM} \pm \mathrm{SEM}$.

blood flow and epithelial development in response to salutary application of GLP-2 (Taylor-Edwards et al., 2011; Connor et al., 2013). In addition, GLP-2 has also been found to reduce intestinal barrier permeability and inhibit inflammation in the gut (Drucker et al., 1996; Burrin et al., 2003; Drucker, 2005). Therefore, it is likely that the preexisting health status of calves enrolled in our study might have been too poor for the OBE60-induced secretion of GLP-2 to improve their intestinal permeability and health.

In summary, our study demonstrates that it is possible to induce the secretion of endogenous GLP-2 in dairy calves and that OBE can be used for such a purpose. However, the increase in GLP-2 secretion did not elicit improvements in permeability and gut function enabling calves to overcome the severity of the enteric challenge. This suggests that the magnitude or timing relative to disease onset of the increase in GLP-2 secretion might have not been adequate to improve intestinal health of calves. In view of these observations, it seems reasonable to propose that further research is warranted to investigate the possibility of improving intestinal integrity through OBE-induced GLP-2 secretion in newborn calves.

\section{ACKNOWLEDGMENTS}

The authors extend appreciation to Lucta S.A. for providing partial financial support and Nouriche Nutrition Ltd. (St. Louis, MO) for donation of the electrolytes. 


\section{REFERENCES}

Araujo, G., C. Yunta, M. Terré, A. Mereu, I. Ipharraguerre, and A. Bach. 2015. Intestinal permeability and incidence of diarrhea in newborn calves. J. Dairy Sci. 98:7309-7317.

Bala, V., S. Rajagopal, D. P. Kumar, A. D. Nalli, S. Mahavadi, A. J. Sanyal, J. R. Grider, and K. S. Murthy. 2014. Release of GLP1 and PYY in response to the activation of G protein-coupled bile acid receptor TGR5 is mediated by Epac/PLC- $\varepsilon$ pathway and modulated by endogenous $\mathrm{H}_{2} \mathrm{~S}$. Front. Physiol. 5:420.

Bjarnason, I., A. Machpherson, and D. Hollander. 1995. Intestinal permeability: An overview. Gastroenterology 108:1566-1581.

Branco Pardal, P., J. P. Lallès, F. André, E. Delval, and R. Toullec. 1995. Assessment of gastrointestinal permeability to small marker probes in the preruminant calf. Reprod. Nutr. Dev. 35:189-200.

Burrin, D., and B. Stoll. 2003. Intestinal nutrient requirements in weanling pigs. Pages 301-335 in The Weaner Pig: Concepts and Consequences. J. R. Pluske, M. W. A. Verstegen, H. Le Dividich, ed. Wageningen Academic Publishers, Wageningen, the Netherlands.

Burrin, D. G., B. Stoll, and X. Guan. 2003. Glucagon-like peptide 2 function in domestic animals. Domest. Anim. Endocrinol. 24:103122

Butler, D. G., and R. C. Clark. 1994. Diarrhoea and dysentery in calves. Pages 91-116 in Escherchia coli in domestic animals and humans. C. L. Gyles, ed. CAB International, Wallingford, UK.

Cameron, H. L., and M. H. Perdue. 2005. Stress impairs murine intestinal barrier function: Improvement by glucagon-like peptide 2 . J. Pharmacol. Exp. Ther. 314:214-220.

Castro, J. J., S. Y. Morrison, A. Hosseinni, J. J. Loor, J. K. Drackley, and I. R. Ipharraguerre. 2016. Secretion of glucagon-like peptide-2 responds to nutrient intake but not glucose provision in milk-fed calves. J. Dairy Sci. 99:5793-5807.

Connor, E. E., S. Kahl, T. H. Elasser, R. L. Baldwin, R. Fayer, M. Santin-Duran, G. L. Sample, and C. M. Evock-Clover. 2013. Glucagon-like peptide 2 therapy reduces negative effects on diarrhea on calf gut. J. Dairy Sci. 96:1793-1802.

Drucker, D. J. 2005. Biologic actions and therapeutic potential of the proglucagon-deprived peptides. Nat. Clin. Pract. Endocrinol. Metab. 1:22-31.

Drucker, D. J., P. Erlich, S. L. Asa, and P. L. Brubaker. 1996. Induction of intestinal epithelial proliferation by glucagon-like peptide 2 . Proc. Natl. Acad. Sci. USA 93:7911-7916.

Groschwitz, K. R., and S. P. Hogan. 2009. Intestinal barrier function: Molecular regulation and disease pathogenesis. J. Allergy Clin. Immunol. 124:3-20.

Guan, X. 2014. The CNS glucagon-like peptide-2 receptor in the control of energy balance and glucose homeostasis. Am. J. Physiol. Regul. Integr. Comp. Physiol. 307:R585-R596.

Hall, E. J. 1999. Clinical laboratory evaluation of small intestinal function. Vet. Clin. North Am. Small Anim. Pract. 29:441-469.

Hartmann, B., A. H. Johnsen, C. Ørskov, K. Adelhorst, L. Thim, and J. J. Holst. 2000. Structure, measurement, and secretion of human glucagon-like peptide-2. Peptides 21:73-80.

Ipharraguerre, I. R., G. Tedó, D. Menoyo, N. D. D. Cabero, J. J. Holst, M. Nofrarias, A. Mereu, and D. G. Burrin. 2013. Bile acids induce glucagon-like peptide 2 secretion with limited effects on intestinal adaptation in early weaned pigs. J. Nutr. 143:1899-1905.
Jain, A. K., B. Stoll, D. G. Burrin, J. J. Holst, and D. D. Moore. 2012. Enteral bile acid treatment improves parenteral nutrition-related liver disease and intestinal mucosal atrophy in neonatal pigs. Am. J. Physiol. Gastrointest. Liver Physiol. 302:G218-G224.

Katsuma, S., A. Hirasawa, and G. Tsujimoto. 2005. Bile acids promote glucagon-like peptide-1 secretion through TGR5 in a murine enteroendocrine cell line STC-1. Biochem. Biophys. Res. Commun. 329:386-390.

Klein, P., T. Kleinová, Z. Volek, and J. Šimůnek. 2008. Effect of Cryptosporidium parvum infection on the absorptive capacity and paracellular permeability of the small intestine in neonatal calves. Vet. Parasitol. 152:53-59.

Klein, P., J. Moravcová, T. Kleinová, Z. Volek, and V. Skřivanová. 2007. Assessment of intestinal permeability in preruminant calves by lactulose/mannitol test. J. Anim. Physiol. Anim. Nutr. (Berl.) 16:43-52.

Littell, R. C., G. A. Milliken, W. W. Troup, R. D. Wolfinger, and O. Schabenberger. 2006. SAS for Mixed Models. 2nd ed. SAS Institute Inc., Cary, NC.

NAHMS (National Animal Health Monitoring System). 2011. Dairy, 2011, Part I: Reference of Dairy Cattle Health and Management Practices in the United States, 2011. Pub. N480.1007. USDA Animal and Plant Health Inspection Service: Veterinary Services, Centers for Epidemiology and Animal Health, Fort Collins, CO.

Sears, C. L. 2000. Molecular physiology and pathophysiology of tight junctions V. assault of the tight junction by enteric pathogens. Am. J. Physiol. Gastrointest. Liver Physiol. 279:G1129-G1134.

Sigalet, D. L., L. E. Wallace, J. J. Holst, G. R. Martin, T. Kaji, H. Tanaka, and K. A. Sharkey. 2007. Enteric neural pathways mediate the anti-inflammatory actions of glucagon-like peptide 2. Am. J. Physiol. Gastrointest. Liver Physiol. 293:G211-G221.

Taylor-Edwards, C. C., D. Burrin, J. Matthews, K. McLeod, J. J. Holst, and D. Harmon. 2010. Expression of mRNA for proglucagon and glucagon-like peptide-2 (GLP-2) receptor in the ruminant gastrointestinal tract and the influence of energy intake. Domest. Anim. Endocrinol. 39:181-193.

Taylor-Edwards, C. C., D. G. Burrin, J. J. Holst, K. R. McLeod, and D. L. Harmon. 2011. Glucagon-like peptide-2 (GLP-2) increases small intestinal blood flow and mucosal growth in ruminating calves. J. Dairy Sci. 94:888-898.

Thomas, C., A. Gioiello, L. Noriega, A. Strehle, J. Oury, G. Rizzo, A. Macchiarulo, H. Yamamoto, C. Mataki, M. Pruzanski, R. Pellicciari, J. Auwerx, and K. Schoonjans. 2009. TGR5-mediated bile acid sensing controls glucose homeostasis. Cell Metab. 10:167-177.

Turton, M. D., D. O'shea, I. Gunn, S. A. Beak, C. M. B. Edwards, K. Meeran, S. J. Choi, G. M. Taylor, M. M. Heath, and P. D. Lambert. 1996. A role for glucagon-like peptide-1 in the central regulation of feeding. Nature 379:69-72.

Ulluwishewa, D., R. C. Anderson, W. C. McNabb, P. J. Moughan, J. M. Wells, and N. C. Roy. 2011. Regulation of tight junction permeability by intestinal bacteria and dietary components. J. Nutr. 141:769-776.

Wøjdemann, M., A. Wettergren, B. Hartmann, and J. J. Holst. 1998. Glucagon-like peptide-2 inhibits centrally induced antral motility in pigs. Scand. J. Gastroenterol. 33:828-832. 